\title{
STRATEGI MARKETING POLITIK CALON INDEPENDEN DALAM MERAIH KEMENANGAN PADA PILKADA WALIKOTA BUKITTINGGI TAHUN 2015
}

\author{
Ade Surya Syahputra, Alia Azmi, Susi Fitria Dewi \\ Program Studi Pendidikan Pancasila dan Kewarganegaraan \\ FIS Universitas Negeri Padang \\ E-mail : adhesuryasyahputra@gmail.com
}

\begin{abstract}
ABSTRAK
Penelitian ini menggambarkan strategi marketing politik calon independen dalam memenangkan pilkada walikota Bukittinggi tahun 2015. Kemenangan calon independen merupakan sesuatu yang jarang terjadi dalam Pilkada. Tujuan penelitian ini adalah untuk mengambarkan strategi politik yang dilakukan calon independen M. Ramlan Nurmantias-Irwandi dalam memenangkan pilkada Bukittinggi pada tahun 2015.Jenis penelitian ini adalah kualitatif dengan pendekatan deskriptif. Pemilihan informan dilakukan dengan teknik Purposive Sampling. Jenis data terdiri dari data primer dan data sekunder, dikumpulkan melalui wawancara dan studi dokumentasi. Uji keabsahaan data menggunakan triangulasi sumber. Analisis data dilakukan melalui pengumpulan data, reduksi data, penyajian data dan penarikan kesimpulan.Hasil penelitian menunjukan bahwa strategi marketing politik yang dilakukan calon independen M. Ramlan NurmantiasIrwandi dalam memenangkan Pilkada Bukittinggi tahun 2015 dengan melakukan strategi Segmentasi, Positioning dan Targeting.strategisegmentasi geografik dilakukan pemetaan terhadap jumlah penduduk yang ada di setiap kecamatan di Bukittinggi dan pemetaan terhadap wilayah yang menjadi basis suara dari pemilihan walikota periode yang lalu, yaitu Pilkada 2010. Kemudian segmentasi demografik dalam hal ini strategi yang dilakukan tim sukses M. Ramlan Nurmantias - Irwandi yaitu dengan memanfaatkan kehadiran dan peran dari kelompok kelompok simpatisan yang berasal dari kelompok masyarakat yang telah di segmentasi.Strategi targeting dilakukan dengan merangkul tokoh tokoh masyarakat dan kelompok masyarakat berdasarkan segmen yang telah ditentukan untuk dijadikan sebagai tim sukses dan juga sebagai kelompok simpatisan Strategi positioning dilakukan dengan menonjolkan diri sebagai calon Independen, menonjolkan visi misi dan program serta menonjolkan image, track record dan figurd dari pasangan Ramlan Nurmantias - Irwandi
\end{abstract}

\section{Kata Kunci : Strategi Marketing Politik, Calon Independen, Pilkada Walikota Bukittinggi}




\begin{abstract}
This study illustrates the political marketing strategy of independent candidates in winning the elections to the mayor of Bukittinggi in 2015. Independent candidate victory is a rare occurrence in the elections. The purpose of this study is to describe the political strategy by independent candidate $M$. RamlanNurmantias-Irwandi in winning the Bukittinggi election in 2015.This type of research is qualitative with descriptive approach. Selection of informants is done by Purposive Sampling technique. This type of data consists of primary data and secondary data, collected through interviews and documentation studies. The data validity test uses source triangulation. Data analysis is done through data collection, data reduction, data presentation and conclusion. The result of the research shows that political marketing strategy by independent candidate $M$. RamlanNurmantias-Irwandi in winning elections in 2015 by Segmentation strategy, Positioning and Targeting.strategy of geographic segmentation is done by mapping the population in each sub-district in Bukittinggi and mapping election of the mayor of the past period, namely Pilkada 2010. Then the demographic segmentation in this strategy by the successful team of $M$. RamlanNurmantias - Irwandi is by utilizing the presence and the role of a group of sympathizers from community groups that have been segmented. Targeting strategy is done by embracing community leaders and community groups based on segments that have been determined to serve as a successful team and also as a group of sympathizers. Positioning strategies are conducted by highlighting themselves as Independent candidates, highlighting the mission and program vision as well as highlighting the image, track record and figurd of RamlanNurmantias - Irwandi
\end{abstract}

\title{
Keywords: Strategy of Political Marketing, Independent Candidate, Election of Mayor of Bukittinggi
}

\section{PENDAHULUAN}

Pelaksanaan pemilihan kepala daerah dalam memilih calon walikota dan wakil walikota dengan skala nasional serentak dilakukan pada 9 desember 2015. Dilaksanakan di 34 Kota di Indonesia yang diikuti dari 86 pasangan calon dari partai politik ataupun gabungan partai politik dan 28 pasangan calon independen. Salah satunya pemilihan calon walikota dan wakil walikota Bukittinggi.Bukittinggi merupakan salah satu kota yang mengadakan pilkada pada 9 Desember 2015, yang di ikuti oleh 5 pasang calon, yaitu H. Taslim, S.Si dan H. Marfendi Dt. Basa Balimo, Febby, SST. Par Dt. Bangso Nan Putiah dan Zul Ifkar Rahim, $\mathrm{H}$. Harma Zaldi, S.Pb dan Ir. Hj. Rahmi 
Brisma, M. Ramlan Nurmatias, SH Dt. Nan Basa dan Irwandi, SH Dt Batujuah dan Ismet Amzis, $\mathrm{SH}$ dan Drs. H. Zulbahri M, M.Pd. Dari 5 pasangan calon, 4 pasang calon diusung dari partai politik dan 1 pasang calon melalui jalur independen.

Tabel 1

Nama Nama Pasangan Calon Pilkada Bukittinggi Tahun 2015

\begin{tabular}{|l|l|l|}
\hline No. & $\begin{array}{l}\text { Pasangan } \\
\text { Calon }\end{array}$ & $\begin{array}{l}\text { Parpol } \\
\text { Pendukung }\end{array}$ \\
\hline 1. & $\begin{array}{l}\text { H. Taslim, } \\
\text { S.Si dan H. } \\
\text { Marfendi }\end{array}$ & PAN, PKS \\
\hline 2. & $\begin{array}{l}\text { H. Febby, } \\
\text { SST. Par dan } \\
\text { Zul Ifkar } \\
\text { Rahim }\end{array}$ & $\begin{array}{l}\text { PPP, PKB, } \\
\text { Hanura }\end{array}$ \\
\hline 3. & $\begin{array}{l}\text { dr. H. } \\
\text { Harma } \\
\text { Zaldi, S.Pb } \\
\text { dan Ir. Hj. } \\
\text { Rahmi } \\
\text { Brisma }\end{array}$ & $\begin{array}{l}\text { Golkar, } \\
\text { Nasdem }\end{array}$ \\
\hline 4. & $\begin{array}{l}\text { M. Ramlan } \\
\text { Nurmatias, } \\
\text { SH dan } \\
\text { Irwandi, SH }\end{array}$ & Independen \\
\hline 5. & $\begin{array}{l}\text { H. Ismet } \\
\text { Amzis, SH } \\
\text { dan Drs. H. } \\
\text { Zulbahri M, } \\
\text { M.Pd }\end{array}$ & $\begin{array}{l}\text { Gerindra, } \\
\text { Demokrat, } \\
\text { PDI-P }\end{array}$ \\
\hline
\end{tabular}

Jika dilihat dari latar belakang kandidat, Pasangan nomor urut satu yaitu Taslim,merupakan mantan anggota DPR-RI dan pengurus DPP PAN berpasangan dengan Marfendi merupakan politisi dari Partai PKS. Pasangan nomor urut dua yaitu Febby pengusaha yang bergerak dibidang tour and travel di Kota Bukittinggi, Febby juga merupakan ketua DPW PKB Sumatera Barat, wakilnya adalah Zulifkar adalah seorang pensiunan Pegawai Negeri Sipil (PNS).

Pasangan nomor urut tiga yaitu Harma Zaldi adalah seorang petahana wakil walikota sebelumnya juga berprofesi sebagai dokter dan wakilnya Rahmi Brisma merupakan politisi PAN dan pernah menjadi wakil ketua DPRD Kota Bukittinggi. Pasangan nomor urut empat yaitu M. Ramlan Nurmatias merupakan seorang pengusaha yang bergerak di bidang infrastruktur dan berpasangan dengan Irwandi merupakan mantan sekretaris daerah Kota Payakumbuh. Pada tahun 2010 M.Ramlan Nurmatias juga pernah mencoba menjadi calon Walikota Bukittinggi berpasangan dengan Azwar Risman Taher, namun usaha tersebut gagal.

Pasangan nomor urut lima Ismet Amziz merupakan mantan walikota periode sebelumnya yang merupakan calon petahana, pada masa kepemimpinan walikota Djufri, Ismet Amziz adalah mantan Wakil Walikota Periode 2005-2010. Setelah Djufri terpilih menjadi anggota DPR-RI Ismet Amziz ikut dalam pemilu 2010-2015 
berpasangan dengan Harma Zaldi dan terpilih sebagai Walikota dan Wakil Walikota Bukittinggi. Wakilnya adalah Zulbahri merupakan mantan anggota DPR-RI dari Partai Gerindra

Dari Rekapitulasi penghitungan hasil suara pemilihan calon walikota Bukittinggi. Calon Walikota dan Wakil Walikota yang tidak diusung oleh partai politik mendapatkan perolehan suara yang terbanyak mengalahkan calon yang dicalonkan oleh partai politik. Pasangan M.Ramlan Nurmatias, $\mathrm{SH}$ Dt. Nan Basa dan Irwandi, SH Dt Batujuah mendapatkan perolehan suara sebanyak 17.870 suara $(41,84 \%)$, diantara perolehan suara dari pasangan calon lainya.

Pasangan H. Taslim, S.Si dan H. Marfendi Dt. Basa Balimo mendapatkan Perolehan suara sebanyak 7.074 suara (16,56\%), Febby, SST. Par Dt. Bangso Nan Putiah dan Zul Ifkar Rahim sebanyak 1.508 suara (3,53\%), H. Harma Zaldi, S.Pb dan Ir. Hj. Rahmi Brisma sebanyak 4.468 suara (10,46\%), dan Ismet Amzis, SH dan Drs. H. Zulbahri Majid, M.Pd sebanyak $11.786(27,60 \%)$.

Kemenangan calon independen M. Ramlan Nurmatias Irwandi, sangat menarik karena dalam sejarah Pilkada Kota Bukittinggi tidak pernah terjadi calon independen mengalahkan calon yang didukung oleh partai politik apalagi calon petahana.Seharusnya calon petahana lebih populer dari calon yang lain. Dari sisi track record Ismet
Amziz pernah menjadi wakil walikota Bukittinggi periode 20052010 dan walikota Bukittinggi priode 2010-2015. Pengalaman ini seharusnya dapat memberi nilai tambah terhadap Ismet Amziz.

Berbeda dengan M. Ramlan Nurmatias calon independen, beliau berprofesi sebagai pengusaha yang bergerak di sektor infrastruktur. M. Ramlan Nurmatias juga pernah menjabat ketua KPU Kota Bukittinggi tahun 2003-2008 yang memiliki andil atas pengembalian uang negara sebanyak 700 juta rupiah , hal ini cukup mengharumkan namanya. Namun dalam modal manusia Muhamad Ramlan Nurmatias masih kalah jauh dari sisi pengalaman dari Ismet Amziz, karena M. Ramlan Nurmatias belum pernah menduduki jabatan politik di Kota Bukittinggi.

Ismet Amziz merupakan ketua DPC Partai Demokrat Kota Bukittinggi. Pada Pilkada 2015 pasangan Ismet Amziz-Zulbahri didukung oleh beberapa partai politik yang mempunyai kedudukan yang kuat di Kota Bukittinggi yaitu Partai Demokrat, PDI-P dan Gerindra. Berbeda dengan pasangan M. Ramlan Nurmantias-Irwandi, yang tidak didukung oleh partai politik, pasangan ini maju dari jalur Independen. Dilihat dari segi modal kelembagaan pasangan Ismet Amziz - Zulbahri lebih unggul dari pasangan M.Ramlan NurmantiasIrwandi.

M. Ramlan Nurmantias dan Ismet Amziz juga cukup terkenal di 
dalam masyarakat Bukittinggi. Kedua kandidat ini merupakan urang kurai yang merupakan penduduk asli Bukittinggi dan kedua kandidat ini juga merupakan seorang datuak dari salah satu suku yang ada di Bukittinggi. M. Ramlan Nurmantias yang bergelar Dt. Nan Basa dari suku kurai koto dan Ismet Amziz yang bergelar Dt. Mangkuto dari suku kurai selayan. kedua kandidat ini memiliki porsi yang sama kuat di kalangan masyarakat Bukittinggi yang memiliki legitimasi atas modal budaya dan modal simbolik.

Namun pasangan M. Ramlan Nurmantias-Irwandi sedikit lebih unggul dari pasangan Ismet AmzizZulbahari. Wakil dari M. Ramlan Nurmantias yaitu Irwandi, merupakan seorang datuak dari suku asli kurai yang bergelar Dt. Batujuah dari suku kurai pisang. Berbeda dengan wakil dari Ismet Amziz yaitu Zulbahri yang tidak memiliki gelar adat kurai dan tidak memiliki modal budaya yang kuat dikarenakan beliau lama berdomisili di provinsi Kepulauan Riau, hal ini membuat Zulbahri tidak terlalu di kenal masyarakat Bukittinggi.

Romi Saputra, didalam penelitian tentang modal politik pasangan independen Muhammad Ramlan Nurmatias-Irwandi pada pilkada kota Bukittinggi tahun 2015 menunjukan bahwa modal politik yang lebih dominan digunakan pasangan Muhamad Ramlan Nurmatias-Irwandi yakni modal sosial, modal ekonomi dan modal budaya, namun yang lebih unggul dihasilkan dari modal sosial, karena dari modal sosial yang dimiliki pasangan Muhamad Ramlan Nurmatias-Irwandi pasangan ini mendapatkan kepercayan oleh banyak masyarakat Kota Bukittinggi Untuk maju sebagai pasangan calon independen, selain mendapatkan kepercayaan dari masyarakat Pasangan Muhamad Ramlan Nurmatias-Irwandi memiliki modal ekonomi yang cukup mempuni dari pasangan calon lainya, dan yang terakhir pasangan ini juga mendapatkan dukungan para pemangku adat masyarakat asli kota Bukittinggi yang di sebut dengan nama Urang Kurai.

Berdasarkan uraian di atas, penulis tertarik untuk mengadakan penelitian tentang strategi strategi yang dilakukan pasangan calon Independen dalam meraih kemenangan dalam pilkada serentak pada pemilihan walikota Bukittinggi pada 9 desember 2015 . Adapun judul penelitian ini adalah: "Strategi Marketing Politk Calon Independen dalam Meraih Kemenangan pada Pilkada Walikota Bukittinggi Tahun 2015 “

\section{METODE PENELITIAN}

Metode penelitian yang peneliti digunakan dalam penelitian ini adalah penelitian kualitatif deskriptif yaitu memberikan gambaran mengenai suatu masyarakat atau sekelompok orang tertentu atau mengambarkan suatu gejala atau hubungan antara dua gejala atau lebih 
(Soehartono,2008:35). Lokasi penelitian ini adalah di Kota Bukittinggi.Jenis data yang digunakan adalah data primer dan data sekunder dengan pengumpulan data melalui wawancara, dandokumentasi. Teknik pengujian keabsahan data melalui teknik triangulasi sumber dan. Analisis data teknik reduksi data, sajian data dan verifikasi data.

\section{HASIL DAN PEMBAHASAN}

Keberadaan marketing sebagai suatu yang penting ketika adanya persaingan, dimana terdapat dua pihak atau lebih yang berkompetisi untuk merebutkan "prestasi" tertentu. Ketika persaingan semakin intens, maka pada saat itu juga semakin tinggi kebutuhan akan marketing sebagai alat untuk memenangkan persaingan. Strategi marketing politik merupakan cara yang tepat untuk menghasilkan kemenangan dalam pemilihan umum. Menurut Firmanzah (2008) dalam Damsar (2012:235), marketing politik merupakan metode yang dapat digunakan untuk meningkatkan pemahaman mengenai masyarakat, sekaligus berguna dalam membuat produk politik yang akan ditawarkan kepada masyarakat

Menurut Newman dalam Lynda Lee Kaid (2015:23), ada kesamaan yang kuat antara bisnis dan politik dalam marketing : pertama, keduanya bergantung pada penggunaan alat dan strategi pemasaran standar seperti riset pemasaran, segmentasi pasar, targeting dan possittioning. Kedua, pemilih dapat dianalisis sebagai konsumen dipasar politik, mengunakan model model dan teori teori yang sama dalam pemasaran yang digunakan untuk mempelajari konsumen dipasar komersial. Ketiga, keduanya berhadapan dalam pasar yang kompetitif dan dengan demikian perlu menggunakan pendekatan serupa untuk menang.

Strategi marketing adalah rencana tindakan yang digunakan untuk melaksanakan serangkaian yang akan menjamin kesuksesan dipasar. Peran strategi marketing adalah untuk memperkuat "posisi" dibenak konstituen yang akan mempengaruhi kesuksesanya dipasar politik, maka strategi marketing dikembangkan dan di implementasikan.(Arterton \& Parloff) dalam Lynda lee kaid (2015:28). Begitu juga dengan strategi yang diterapkan Calon Independen M. Ramlan NurmantiasIrwandi dalam memenangkan Pilkada Bukittinggi 2015. Firmanzah (2008:212) menyebutkan dalam marketing politik dapat mengunakan strategi segmentasi, strategi targeting dan strategi positioning, Strategi ini dapat mengantarkan pasang calon kandidat menjadi pemenang dalam sebuah pemilihan.

Dapat dilihat bahwa dengan mengunakan strategi segmentasi, strategi targeting dan strategi positioning, mengantarkan M.Ramlan Nurmantias-Irwandi 
menjadi pemenang dalam Pilkada Bukittinggi Tahun 2015.

\section{Segmentasi}

Segmentasi merupakan suatu kelompok yang memberikan tanggapan yang sama. Segmentasi bertujuan untuk mengenal lebih jauh kelompok kelompok pemilih dalam masyarakat. Hal tersebut bermanfaat untuk mencari peluang, menganalisa prilaku pemilih dan lain sebagainya. para kandidat perlu memahami konsep segmentasi karena berhadapan dengan pemilih yang sangat heterogen. Para kandidat dapat memberikan tawaran politik yang efektif bila mereka mengetahui karakter yang menjadi sasaran. Menurut Lynda Lee kaid (2015:27) menjelaskan dalam segmentasi pasar digunakan untuk memilih kelompok kelompok orang yang ditargetkan dengan daya tarik dari kandidat

Strategi segmentasi yang digunakan M.Ramlan NurmantiasIrwandi dalam Pilkada Bukittinggi Tahun 2015 adalah segmentasi geografik dan segmentasi demografi. Menurut Firmanzah (2008:186) Segmentasi geografik adalah pengelompokan masyarakat berdasarkan geografis dan kerapatan populasi. Strategi segmentasi geografik yang digunakan M.Ramlan NurmantiasIrwandi adalah dengan melakukan pemetaan terhadap jumlah penduduk dan pemetaan terhadap basis suara pilkada Bukittinggi tahun 2010.
Dari pemetaan yang dilakukan dapat diketahui dimana wilayah, $\mathrm{M}$. Ramlan Nurmantias ini pernah unggul dalam pilkada Bukittinggi tahun 2010, hal tersebut digunakan untuk menjaga tempat tersebut sebagai basis suara terbanyak untuk pasangan Ramlan NurmantiasIrwandi, salah satunya kelurahan Manggis Ganting yang merupakan tempat kampung Ramlan Nurmantias. Di kelurahan manggis Ganting Ramlan Nurmantias mendapatkan perolehan suara terbanyak pada pilkada 2010.

Selain itu pemetaan ini juga berguna untuk mengetahui dimana tempat M.Ramlan Nurmantias memiliki perolehan suara terendah, dalam rekapitulasi perhitungan suara pada pilkada 2010. Salah satunya di kecamatan ABTB, menjadi tempat suara terendah bagi M,Ramlan Nurmantias pada pilkada 2010. Di kecamataan ABTB M.Ramlan Nurmantias pada pilkada 2010 mengalami kekalahan yang cukup besar dari pada kecamataan lainya. hal tersebut di jadikan acuan agar tim sukses pada kelurahan tersebut dapat berkerja lebih ekstra untuk menarik simpati dan dukungan masyarakat disana. Pemetaan Juga dilakukan terhadap jumlah penduduk Bukittinggi dari pemetaan tersebut nanti akan terlihat jumlah penduduk yang memiliki hak suara di setiap kecamatan. Hal tersebut berguna untuk menentukan kecamataan mana yang menjadi sasaran atau wilayah kantong suara dari pasangan M. Ramlan Nurmantias- 
Irwandi ini. Kecamataan yang memiliki jumlah penduduk terbanyak dan terpadat terdapat di Bukittinggi lebih difokus mendapatkan dukungan dan perolehan suara disana.

Penyebaran penduduk di Bukittinggi di setiap kecamataan memang kurang merata. Dari 3 kecamataan yang ada di Bukittinggi, Jumlah penduduk paling banyak berada di kecamataan Mandiangin Koto Selayan (MKS) dengan jumlah penduduk 50.253 Jiwa, kecamatan MKS mempunyai penduduk paling banyak dari 2 kecamatan lainnya, dengan luas wilayah yang cukup besar dari kecamataan lainya. Sedangkan jumlah penduduk terpadat terdapat pada kecamataan Guguak Panjang dengan jumlah penduduk 45.061 Jiwa. Kecamataan Guguak Panjang menjadi kecamatan dengan jumlah penduduknya yang padat dengan luas yang tidak begitu luas. Dua kecamataan ini di fokuskan menjadi tempat kantong suara bagi pasangan M.Ramlan Nurmantias-Irwandi dalam memenangkan Pilkada 2015.

Menurut Firmanzah (2008:186) Segmentasi demografi dapat dibedakan berdasarkan umur, jenis kelamin, pekerjaan, dan kelas sosial. Masing masing kategori memiliki karakteristik yang berbeda Segmentasi demografi yang dipergunakan oleh M. Ramlan Nurmantias - Irwandi adalah mengelompokan kelompok kelompok masyarakat yang ada di Bukittinggi. seperti kelompok Ibu ibu pengajian masjid taqlim, Ibu ibu
PKK, kelompok pedagang, ikatan kedaerahan, club mobil dan motor. Pengelompokan masyarakat berdasarkan demografi bertujuan untuk mencari simpatisan dari setiap kelompok kelompok masyarakat ada. Sehingga kelompok ini lah sebagai media yang bisa mensosialisasikan pasangan $\mathrm{M}$. Ramlan Nurmantias - Irwandi kepada kelompoknya masing masing.

Kehadiran kelompok simpatisan akan lebih memudahkan tim sukses untuk mensosialisasikan pasangan M. Ramlan Nurmantias- Irwandi di lingkunganya masing masing masyarakat Bukittinggi. Kelompok simpatisan ini juga memiliki peranan yang cukup penting bagi M. Ramlan Nurmantias-Irwandi dalam menerapkan strategi marketing dalam meraih kemenangan pada pilkada Bukittinggi tahun 2015.

\section{Targeting}

Targeting adalah pemilih kepada suatu segmen tertentu yang ingin dicapai, digarap secara intensif untuk diraih sebagai pendukung utama. Selain itu, targeting dapat diartikan sebagai pemilih salah satu atau beberapa segmen yang akan dibidik untuk mencapai sasaran obyektif. Sebelum menentukan target atau sasaran, terlebih dahulu kita memulai dengan memahami wilayah pemilih.

Strategi targetting dilakukan M.Ramlan Nurmantias-Irwandi adalah merangkul tokoh tokoh masyarakat dan kelompok 
masyarakat berdasarkan segmentasi yang telah ditentukan untuk dijadikan tim sukses ataupun simpatisan.

Strategi mengandeng atau membawa masuk tokoh tokoh masyarakat kedalam lingkaran tim sukses dimaksud kan agar tokoh tokoh tersebut dapat menjadi ujung tombak pemenangan didaerah sekitar tokoh tokoh tersebut. Dengan itu diharapkan para tokoh akan dapat mempengaruhi dan mengajak masyarakat mereka agar turut memilih pasangan Ramlan Nurmantias-Irwandi.

Dalam bagian strategi targetting dapat dilihat bagaimana M. Ramlan Nurmantias - Irwandi bisa memanfaatkan suatu segmen atau kelompok tertentu untuk dijadikan sebagai pendukung utama dalam mempengaruhi para pemilih. Merangkul dan melibatkan tokoh tokoh masyarakat sebagai tim sukses ataupun simpatisan dimaksudkan agar tokoh tersebut dapat menjadi penarik masa di daerah sekitar tokoh tokoh tersebut. selain itu juga dengan menghadirkan tokoh tersebut didalam pertemuan ataupun silaturrahmi yang dilakukan tim sukses dan pasangan calon bersama masyarakat, sehingga timbul ketertarikan masyarakat untuk memilih pasangan Ramlan Nurmantias-Irwandi.

Firmanzah

(2008:214)

menyatakan meskipun jumlah kelompok masyarakat tidak memiliki besaran yang signifikan, pengaruh mereka dalam membentuk opini publik jelas jelas sangat besar. Jadi tokoh tokoh masyarakat dari kelompok kelompok masyarakat ini layak untuk di dekati oleh kontestan pemilu.

Menurut Lynda Lee Kaid (2015:28) menjelaskan bahwa strategi pemasaran akan sukses jika dimulai dengan perekrutan calon yang layak. Artinya untuk mensukseskan strategi marketing politik M. Ramlan NurmantiasIrwandi harus menyeleksi siapa siapa saja orang yang akan di jadikan sebagai tim suksesnya, seharusnya tim sukses maupun simpatisanya ini harus dari tokoh tokoh masyarakat. Tokoh tokoh masyarakat merupakan orang orang yang dihormati ataupun disegani yang memberikan pengaruh di dalam masyarakat. Jika tokoh tokoh masyarakat bergabung kedalam tim sukses maupun simpatisan akan memudahkan $\mathrm{M}$. Ramlan Nurmantias-Irwandi untuk menyampaikan produk produk politiknya kepada masyarakat.

\section{Positioning}

Positioning adalah tindakan untuk menancapkan citra tertentu ke dalam benak para pemilih agar tawaran produk politik dari suatu konstestan memiliki posisi yang khas dan jelas. Dalam iklim persaingan, seorang kandidat harus mampu menempatkan produk politik dan image politik harus memiliki sesuatu yang berbeda dibandingkan dengan produk produk politik lainya. keseragaman produk dan image akan menyulitkan masyarakat dalam 
mengidentifikasi suatu kandidat, karena semua produk dan image politiknya berbagi karakteristik yang sama (Firmanzah 2008:190)

Firmanzah

(2008:215)

menyatakan bahwa positioning sangat penting dilakukan untuk membantu pemilih dalam membedakan suatu kontestan dengan para pesaingnya. Ketepatan membuat positioning dalam hal yang menyangkut imagepolitik, produk politik, pesan politik, dan program kerja akan membantu dalam menciptakan identitas politik.

Dalam strategi positioning atau sesuatu yang membedakan antara pasangan M. Ramlan NurmantiasIrwandi dengan pasangan lainya adalah pasangan kandidat lain di dukung dan dicalonkan dari partai politik sedangkan pasangan $\mathrm{M}$. Ramlan Nurmantias-Irwandi tidak didukung oleh partai politik dan mencalonkan diri dari jalur Independent .

Sebagai calon Independen, Muhammad Ramlan Nurmantias Irwandi mempunyai karakteristik yang berbeda dari kandidat lainya. Dari 5 pasangan calon yang ikut dalam Pilkada Bukittinggi 2015, M. Ramlan Nurmantias-Irwandi yang mencalonkan diri dari jalur independen. Berbeda dengan kandidat lain yang mencalonkan diri dari partai politik. pasangan $\mathrm{M}$. Ramlan Nurmantias-Irwandi secara tidak langsung telah mempunyai karakteristik karena pasangan ini lah satu satunya yang merupakan pasangan Independen. Masyarakat akan lebih cepat mengenal $\mathrm{M}$.
Ramlan Nurmantias-Irwandi ketimbang kandidat lainya.

Menurut Firmanzah (2008:271) Kampanye pemilu adalah periode yang diberikan oleh panitia pemilu kepada semua kontestan, baik partai politik maupun perorangan untuk memaparkan program program kerja dan mempengaruhi opini publik sekaligus memobilisasi masyarakat agar memberikan suara kepada mereka sewaktu pencoblosan.

Pasangan M.Ramlan Nurmantias-Irwandi juga menonjolkan tentang visi misi dan programnya jika terpilih menjadi walikota Bukittinggi nantinya. Firmanzah (2008:217) menjelaskan bahwa permasalahan dan persoalan yang dialami dan dirasakan masyarakat dijadikan dasar dan acuan inti dalam menyusun program kerja yang di tawarkan. Pasangan M.Ramlan NurmantiasIrwandi memfokuskan tentang permasalahan pendidikan, pariwisata, kesehatan dan perdagangan. Yang merupakan persoalan yang di hadapi masyarakat. Selain itu M.Ramlan Nurmantias-Irwandi juga mengangkat permasalahan permasalahan yang menjadi pusat perhatian masyarakat pada masa Pilkada. Mengunakan satu visi sentral yang terhubungan dengan isu isu dan kepribadian kandidat akan memudahkan komunikasi dengan pemilih mendefinisikan esensi dari kampanye calon (Lynda Lee Kaid 2015:31) 
Strategi yang akan diterapkan tidak akan dapat berhasil jika tim sukses ataupun kandidat tersebut tidak ataupun belum mengenal target atau objek dari strategi tersebut. oleh karena itu, tim sukses ataupun kandidat seharusnya dapat melakukanya berbagai pendekatan dengan massa, sehingga apaa aja yang dibutuhkan oleh massa bisa dijadikan sebagai tawaran dalam isu kampanye dilakukan oleh tim sukses ataupun kandidat. Apa yang dibutuhkan masyarakat bisa dijadikan isu isu politik di dalam kampanye. Tawaran dari isu isu kampanye diharapkan bisa menarik simpati masyarakat. Isu politik merupakan kebijakan yang didukung calon dan janji janji untuk memberlakukanya jika terpilih (Lynda Lee Kaid 2015: 24)

Menurut Firmanzah (2008:242) untuk membangun image politik dan sampai di masyarakat sesuai dengan apa yang diharapkan bukanlah hal yang mudah dan dapat cepat dicapi. Untuk membangun image yang baik dimasyarakat harus dilakukan seorang kandidat harus membangun image jauh jauh hari sebelum mengikuti pemilihan. Tim sukses M.Ramlan NurmantiasIrwandi juga mengangkat tentang image, Figur serta track record dari pasangan M. Ramlan Nurmantias Irwandi, agar masyarakat lebih dekat mengenal sosok calon pemimpinya nantinya. Image, track record dan Figur yamg dimiliki M.Ramlan Nurmantias -Irwandi dijadikan modal utama untuk menarik perhatian masyarakat dan membedakan dari kandidat lainya.

Menurut Lynda Lee Kaid (2015:24) citra sosial merupakan penggunaan stereotip untuk menarik pemilih dengan membuat hubungan antara calon dan segmen tertentu dalam masyarakat. citra merupakan gambaran tentang objek (produk, sosok/figur) dibenak khalayak. Citra merupakan "mental picture" yang dibentuk akibat terpaan stimulus seperti kampanye, iklan, promosi penualan, eksibisi ( Suyono 2014:39)

Menurut Lynda Lee Kaid (2015:27) positioning adalah wahana yang memungkinkan calon untuk menyampaikan citra mereka kepada pemilih dalam sorotan yang terbaik. Faktor dari ketokohan seorang kandidat juga sangat mempengaruhi hasil dari pemilihan. seorang calon atau kandidat seharusnya merupakan orang orang yang telah dikenal oleh masyarakat, baik itu dari pengalaman memimpin calon tersebut ataupun prestasi yang pernah diraih calon tersebut. hal tersebut disebabkan karena seorang pemilih akan lebih mudah untuk menilai seorang yang telah dikenalnya dan memilih kandidat yang memiliki track record yang baik pula. Lynda Lee Kaid menyebutkan bahwa kepribadian calon mencakup pentingnya kepribadian calon dalam membantu memperkuat dan memproduksi gambar dalam pikiran pemilih, Meskipun faktor dari figur kandidat yang dinilai baik oleh massa dapat mempengaruhi perolehan suara, tidak dapat 
dipungkuri bahwa tanpa adanya strategi yang baik tidak akan menghasilkan kemenangan dalam pemlihan.

\section{KESIMPULAN}

Berdasarkan temuan dan pembahasan terhadap strategi marketing politik calon independen dalam meraih kemenangan pada pilkada Bukittinggi tahun 2015 dapat disimpulkan bahwa kemenangan pasangan M.Ramlan NurmantiasIrwandi tidak lepas dari pengunaan strategi marketing politik. Strategi segmentasi, targeting dan positioning mengantarkan M.Ramlan Nurmantias dan Irwandi sebagai pemenangan dalam pilkada Bukittinggi tahun 2015.
Strategi segmentasi yang digunakan M.Ramlan Nurmantias dan Irwandi adalah mengelompokan segmen segmen yang ada di dalam masyarakat. Setelah menentukan segmen yang akan di pilih, maka digarap secara intensif untuk di raih sebagai pendukung utama. Pendukung utama dalam strategi targeting ini adalah tokoh tokoh masyarakat dan kelompok kelompok masyarakat berdasarkan segmen yang telah di tentukan tersebut yang dijadikan tim sukses maupun simpatisan. Strategi positioning merupakan strategi yang membedakan M.Ramlan Nurmantias-Irwandi dengan kandidat lainya baik dari image, track record, Figur maupun karakteristiknya.

\section{DAFTAR PUSTAKA}

Cangara, Hafied , 2009, KomunikasiPolitik, Jakarta: Rajawali Pers Firmanzah. 2008. Marketing Politik. Jakarta : Yayasan Obor Indonesia Lee Kaid. Linda. 2015. Handbook penelitian komunikasi politik. Bandung: Nusa Media.

Saputra.Romi. 2017. Skripsi : Modal Politik Pasangan Independen Muhammad Ramlan Nurmantias-Irwandi Pada Pilkada Kota Bukitttinggi Tahun 2015 . Universitas Andalas : Padang

Suyono.2014. Jurnal : Pencitraan Bakal Capres 2014 dalam Media Online. Vol 6 no. 1

Undang Undang Republik Indonesia no. 8 tahun 2015 tentang perubahan atas UU no. 1 tahun 2015 tentang penetapan peraturan pemerintah penganti undang undang no.1 tahun 2014 tentang pemilihan Gubernur,Bupati dan Walikota 